\title{
A drift-correlated ground motion intensity measure: application to steel frame buildings
}

Luis A. Pinzón (luis.pinzon@upc.edu) (corresponding author)

Department of Civil and Environmental Engineering

Universitat Politècnica de Catalunya, Barcelona Tech, Spain

ORCID: 0000-0003-3128-7158

Yeudy F. Vargas-Alzate (yeudy.felipe.vargas@upc.edu)

Department of Civil and Environmental Engineering

Universitat Politècnica de Catalunya, Barcelona Tech, Spain

Luis G. Pujades (lluis.pujades@upc.edu)

Department of Civil and Environmental Engineering

Universitat Politècnica de Catalunya, Barcelona Tech, Spain

ORCID: 0000-0002-2619-0805

Sergio A. Diaz (alberto.diaz@Ujat.mx)

Academic Division of Engineering and Architecture

Universidad Juárez Autónoma de Tabasco, México

ORCID: 0000-0003-3736-9154

\section{Keywords}

Steel frame buildings; maximum inter-story drift; intensity measures; non-linear dynamic analysis; destructiveness potential 


\begin{abstract}
Estimations of seismic risk in urban areas should include quantifications of the expected damage to civil structures subjected to earthquakes. In buildings, this quantification depends on the maximum inter-story drift (MIDR), among other aspects. In this study, the correlation between several intensity measures (IMs) and the maximum inter-story drift of steel structures was investigated. Three steel frame buildings of 3, 7 and 13 stories were used as a testbed. These buildings were modelled as 2D framed structures. For the seismic hazard, forty strong ground motion pairs were selected ( 80 individual horizontal components) from the Italian database. These records were scaled to a specific peak ground acceleration (PGA) and matched to a design spectrum from Eurocode 8. Nonlinear dynamic analysis was used to estimate the seismic response of the structures. Thus, 720 nonlinear dynamic analyses (NLDA) were performed [3 structures $\times(80$ as recorded accelerograms +80 scaled records +80 matched records $)]$. Preliminary results indicate that PGA and MIDR show the worst correlation. A higher correlation was observed for peak ground velocity, root-mean-square velocity and specific energy density intensity-based measures. Finally, a new IM, which is highly correlated with MIDR, is proposed. This IM is called IDPGV and considers both the PGV and the significant duration.
\end{abstract}

\title{
1. Introduction
}

Over the last decade, a number of high-magnitude earthquakes have caused hundreds of thousands of fatalities, made millions of people homeless and caused considerable economic losses. Earthquakes such as those in Maule (Chile, 2010), Christchurch (New Zealand, 2011), Tohoku (Japan, 2011), Emilia (Italy, 2012), Umbria (Italy, 2016), Ecuador (Ecuador, 2016) and Mexico City (Mexico, 2017) generated economic losses in the order of $\$ 400$ billion [1]. Moreover, depending on the vulnerability of the stricken area, a single earthquake can cause hundreds of thousands of fatalities. This was the case in the 2010, $\mathrm{Mw}=7.0$, Haiti earthquake [2]. The examples confirm the need for further research on the negative 
consequences of these geohazards. Advanced tools to improve the estimation of seismic risk could contribute significantly to mitigating the negative consequences of earthquakes.

In this context, identification of the potential destructiveness of an earthquake is a topic that has captured the attention of seismologists and engineers for almost a century. Accurate characterization of the seismic potential of a region is fundamental for estimating and reducing its seismic risk. Currently, acceleration response spectra functions [3-5] are the preferred method in the design of new structures and assessments of the performance of existing ones. For design purposes, the design response spectrum (DRS) is used, which is related to the location of the structure. The DRS is generally provided by the seismic codes and guidelines of the construction area. For assessment purposes, the uniform hazard spectrum (UHS) is normally used to quantify the seismic hazard of the area. Over the years, a set of damage-related intensity measures (IMs) have also been developed. To a greater or lesser extent, these IMs are related to the expected seismic damage of a structure. Identifying the IM that is most strongly correlated to the expected damage of a structure is of interest, since it can contribute to improving the estimation of seismic risk.

The degree of correlation between several IMs and the expected damage of a structure were studied. To achieve this, three steel frame buildings with varying numbers of stories were analyzed through nonlinear dynamic analyses (NLDA). Eighty horizontal accelerograms (40 records, two horizontal components) from the Italian Accelerometric Archive (ITACA) [6] were used to characterize the seismic actions. These ground motion records were carefully selected in terms of the duration of the strong phase to identify whether this variable influences the building performance. However, the NLDA was performed using the original, scaled and spectrum-matched records as will be explained later. Thus, 720 NLDA were carried out and the MIDR and the damage index of Park and Ang, PA, [7] were calculated. Then, the correlations between the IMs and the MIDR were estimated and compared. Finally, a new IM, which is highly correlated with the MIDR, was proposed. This new IM is a combination of two well- 
known seismic parameters: the peak ground velocity (PGV) and the significant duration. The use of more than one seismic parameter to define the damage potential of earthquakes to structures is a significant novelty, allowing alternative methods such as Artificial Neural Networks to be undertaken $[8,9]$. The performance of this IM was also validated through probabilistic NLDA. One of its main advantages is its independence from the properties of the analyzed structure and its high correlation with the MIDR.

\section{Intensity measures}

The efficiency of some IMs as indicators of potential structural damage were evaluated in this study. For this purpose, several IMs were estimated (see Table 1). They were selected because they are the most commonly used in the development of seismic hazard studies through ground motion prediction equations [10], and in the estimation of expected damage [11,12]. In the following section, the IMs that were considered are described briefly.

\subsection{Intensity measures based on ground motion time histories}

In 1934, Benioff [13] defined an earthquake's destructiveness measure in terms of the energy obtained through the relative displacement response spectrum. After this paper, several measures were devised based on the energy content of the signal. For instance, Arias intensity [14] is a measure of the severity of the ground motion and is defined by the following equation:

$$
I_{A}=\frac{\pi}{2 g} \int_{t_{i}}^{t_{f}} a(t)^{2} d t
$$

where $g$ is the acceleration due to gravity, $t_{i}$ is the beginning of the record, $t_{f}$ is the total duration of the record and $a(t)$ represents the acceleration time history of the earthquake. 
Many authors used this measure to define the significant duration $(\Delta)$ of a ground motion [1518]. Significant duration is based on the energy accumulation and is defined as the interval over which some proportion of the total energy is accumulated [19]. This interval is considered the "strong phase" of a ground motion. In this study, the thresholds of $5 \%$ and $95 \%$ of Arias intensity mark the beginning $\left(t_{5 \%}\right)$ and end (t95\%) of the phase, as proposed by Trifunac and Brady [18] (see Fig. 1).

Housner [17] and Dobry et al. [20] suggested that ground motion can be characterized by the quadratic mean of the acceleration time histories (see Equation 2).

$$
\operatorname{acc}_{R M S}=\sqrt{\frac{1}{\Delta} \int_{t_{5 \%}}^{t_{95 \%}} a(t)^{2} d t}
$$

where $\Delta$ is the duration of the strong phase (5-95\% of Arias intensity), also known as the significant duration, $t 5 \%$ is the initial time of the strong phase and $t 95 \%$ is the final time of the strong phase of an acceleration time history, $a(t)$. Moreover, the root mean square of the velocity time histories, $v(t)$, has been associated with damage in several studies (Equation 3) [11,12].

$$
\text { vel }_{R M S}=\sqrt{\frac{1}{\Delta} \int_{t_{5 \%}}^{t_{95 \%}} v(t)^{2} d t}
$$

Another interesting measure is the Specific Energy Density (SED) [21,22], which is defined as the integral of the square velocity time history $v(t)$ in the interval $t_{i}-t_{f}$ (see Equation 4 ).

$$
S E D=\int_{t_{i}}^{t_{f}} v(t)^{2} d t
$$

Park et al. [23] developed a relationship between the destructiveness potential of an earthquake ground motion (Characteristic intensity, $I_{C}$ ) and the structural damage of reinforced concrete buildings, 
using the damage index proposed by Park and Ang [7]. The $I_{C}$ was defined by means of the following equation:

$$
I_{c}=\operatorname{acc}_{R M S}{ }^{1.5} \sqrt{t_{f}}
$$

The Cumulative Absolute Velocity (CAV) intensity measure was proposed by Reed and Kassawara [24] and has also been used to state the destructive potential of earthquakes.

$$
C A V=\int_{t_{i}}^{t_{f}}|a(t)| d t
$$

\subsection{Intensity measures based on peak responses}

Another group of IMs based on the peak response of a single-degree-of-freedom (SDOF) system has been considered in assessments of the seismic behaviour of structures. These IMs have been used to build up the design response spectrum in many seismic regulations. Thus, the Peak Ground Acceleration (PGA), the Peak Ground Velocity (PGV) and the elastic spectral acceleration at the fundamental period of the structure, SaT1, were included in the correlation analysis. These IMs are listed in Table 1.

Note that the IMs described in Table 1 have been correlated with expected seismic structural damage [11,25-27]. In these studies, the aim was to obtain an IM that properly represents the destructive potential of an earthquake. Such a measure would help in the development of more accurate seismic hazard studies and, therefore, more precise seismic design methods. Thus, the described IMs will be correlated with the MIDR. Note that this engineering demand parameter (EDP) has been widely correlated with damage states in seismic risk assessment methods, such as Hazus [28]. 


\section{Structural models}

Three steel buildings of 3, 7 and 13 stories were analysed in this study (Fig. 2). The buildings have special moment frames as a seismic-force-resisting system with "wide flange" sections for beams and columns, according to ASTM A992 [29] (Fig. 2). These elements are joined through prequalified connections [30] of fully restrained type. The buildings were designed for office use based on the provisions in AISC-34110 [31]. Buckling in columns was controlled in the design. The special moment frames satisfy the AISC criterion strong-column-weak-beam and the structural sections of the columns meet the slenderness criterion presented in AISC-341-10 [31]. The weight of the structure, the architectonic finishes and facilities were considered as dead loads. The live loads were selected according to ASCE 7-10 [32] provisions for office use.

These buildings were modelled as frame type members with plastic hinges at their ends using Ruaumoko 2D software [33]. The plastic hinges follow a Bilinear Hysteresis rule with hardening and strength degradation based on the ductility factor [33]. The strength and ductility values for the hysteresis rule were calculated according to the modified Ibarra-Medina-Krawinkler (IMK) model [34-36]. The backbone curve of the modified IMK model is defined by three strength parameters $\left(M_{y}=\right.$ effective yield moment, $M_{c}=$ capping moment strength or post-yield strength ratio $M_{c} / M_{y}=1.1$ and $M_{r}=k \cdot M_{y}, k=0.4$, residual moment). These strength parameters are obtained from the steel section's properties: the plastic modulus (depends on the W type sections used), yield strength (345 MPa), and elastic modulus (200,000 MPa). The ductility of the structural sections in the modified IMK model are defined by the four deformation parameters: $\theta_{y}=$ yield rotation, $\theta_{p}=$ pre-capping plastic rotation for monotonic loading difference between yield rotation and rotation at the maximum moment, $\theta_{p c}=$ post-capping plastic rotation difference between rotation at the maximum moment and rotation at complete loss of strength and $\theta_{u}=$ ultimate rotation capacity. Two per cent Rayleigh damping was used for the first and last vibration modes as recommended for steel structures. Input motions were applied directly at the base of 
the buildings. The base of the resisting frames is fixed with all degrees of freedom restrained. $\mathrm{P}-\Delta$ effect was considered in the analysis. Ruaumoko allows modelling structures where the displacements are sufficient to require a large displacement analyses or where the axial forces in members affect their stiffness. In large displacement analyses the coordinates, as well as the axial forces in the beam or wall members and the changes in geometry in the members, are updated at every time-step. This procedure is computationally expensive, but is important if the structure is undertaking large displacements. As the response of the buildings analyzed herein can achieve MIDR significantly greater than $1 \%$, this approach has been considered within the simulations to consider the P- $\Delta$ effect. The predominant periods of the buildings are 0.6 (3-story), 1.2 (7-story) and 1.9 (13-story) seconds. Further details about the modelling considerations can be found in Diaz et al. [37].

\section{Ground motion records}

To perform the NLDAs, a set of ground motion records were selected as a function of the duration of their strong phase. The ITACA database was used for this purpose. The horizontal components of the records were used in the analysis. Records were considered with a duration of around 4, 5, 7 and 30 seconds (see Table 2). This selection criterion was aimed at evaluating the influence of the duration of the earthquake record on the damage of buildings. The record set included 40 component pairs of horizontal ground motions (80 individual components, see Table 2). Note that the duration values used for selecting the earthquake records were taken directly from the database catalogue. In the database, the effective duration [19] is used as reference. Then, we estimated the significant duration for each component (see Table 1). As mentioned above, the analyses were performed using original, scaled and spectrally matched ground motions. The significant duration was recalculated for the spectrally matched records. In order to obtain the scaled records, the selected ones were normalized by the peak ground acceleration (PGA) and multiplied by $700 \mathrm{~cm} / \mathrm{s}^{2}$. The $700 \mathrm{~cm} / \mathrm{s}^{2}$ value is used as a reference, since 
buildings begin to be damaged around this PGA. The spectrally matched records were adjusted to an elastic design spectrum defined in Eurocode 8 [38]. Namely, the design spectrum for rock, a base acceleration of $700 \mathrm{~cm} / \mathrm{s}^{2}$, a seismically active region type I (earthquake magnitudes over 5.5) and a 5\% damping value was used as a target. The spectral matching method used in this paper was developed by Pujades (personal communication, 2015) and has been used in previous studies [39,40]. A comparison showing the effectiveness of the matching procedure can be seen in Fig. 3.

\section{Correlation between the IMs and the MIDR}

The IMs were estimated massively with a program developed in MATLAB [41] and they were checked with the commercial software SeismoSignal [42], with excellent agreement. The correlation values between the IMs listed in Table 1 and the MIDR obtained after performing the 720 NLDAs [3 structures $\times(80$ as-recorded accelerograms +80 scaled records +80 matched records $)]$ are presented in Fig. 4 . The square of the correlation coefficient $\left(\mathrm{R}^{2}\right)$, which is also called the coefficient of determination, was used as an indicator. The results as a function of the PGA are shown in Fig. 4a. In this figure, the results corresponding to the scaled records can be clearly identified at a PGA value of $700 \mathrm{~cm} / \mathrm{s}^{2}$. It is interesting that earthquakes with similar PGA values may produce very different MIDR. SAT1, accRMS, $\mathrm{I}_{\mathrm{A}}$, IC and CAV present an $\mathrm{R}^{2}$ value of around 0.80 . For the $\mathrm{IM} \mathrm{SA}_{\mathrm{T} 1}$, note that a better correlation would have been obtained if the regression analyses were carried out independently for each building. Although 0.80 is a good enough correlation, there are other IMs with higher correlation values. Actually, the IMs with better correlation values are the PGV, vel $\mathrm{RMS}$ and SED. Among these highly correlated IMs, the PGV is the easiest to obtain. Thus, the PGV seems to be a good measure to predict expected damage since it is directly obtained from the ground motion and is independent of the period of the buildings.

In Table 3, a summary of the $\mathrm{R}^{2}$ values obtained after performing correlations with different groups of ground motion records is shown. Values obtained with the original records reflect similar results to 
the correlation obtained with all the records. As expected, when the records are scaled to the same PGA, the correlation with this IM is lost. The values obtained with the matched ground motions has shown that the correlation is null between IMs and the MIDR, since IMs are conditioned to a target spectrum. Finally, the values obtained with the group of original plus scaled records reveal that the correlation is maintained when the matched records are added (although these have no correlation with the MIDR). This is because the matched records generate similar MIDR values and therefore similar values on IMs, which avoids a decrease in the correlation with all the records. Table 4 shows the type of equation used and the coefficient that fulfils the minimization condition from the 720 NLDA. In the next section, a new IM which is highly correlated with the MIDR and is based on the PGV and the significant duration is presented.

\section{New IM}

In this section a new IM is proposed based on the results after performing the correlations with the MIDR. This IM is based on the PGV but also includes the significant duration $(\Delta$, between $5-95 \%$ of the Arias intensity) as a variable (see Equation 7) and is called ID-PGV. This IM is independent of the period of the oscillator. This new IM was proposed because there is certain level of correlation between the MIDR and the significant duration of the scaled records (see Fig. 5). Thus, based on this correlation and considering the high correlation between the PGV and the MIDR, this new IM is defined according to the following equation:

$$
I_{D-P G V}=P G V^{\alpha} \Delta^{\beta}
$$

where $\alpha$ and $\beta$ are coefficients obtained by minimizing the mean square error between the MIDR and the values provided by this equation. $\mathrm{PGV}$ is in $\mathrm{m} / \mathrm{s}$ and $\Delta$ in $\mathrm{s}$. After the minimization procedure, $\alpha=1.5$ and $\beta=0.5$. Notably, in this IM the significant duration is a relevant variable. 
The results obtained after correlating the ID-PGV with the MIDR are shown in Fig 6. From these results it can be concluded that the proposed IM is highly correlated with the MIDR. Actually, the highest coefficients of determination were obtained after the regression analysis, compared with all the IMs studied (see Tables 3 and 5). In Fig. 6b, damaged buildings are highlighted in red whilst those that do not suffer damage are in black. This identification is based on the damage index (DI) of Park and Ang. Therefore, if DI $>0.1$ then the point will be red otherwise it will be black. Most of the buildings suffered damage (DI $>0.1)$ when the inter-story drift reached the threshold of 0.015 . Regarding ID-PGV values, damage appears at a value close to 1 whilst the maximum value is around 6 .

Finally, Fig. 7 shows the distribution of the $\mathrm{R}^{2}$ values according to the IM for each building type. The $\mathrm{R}^{2}$ values for the proposed IM are very similar regardless of the building analyzed and the types of simulations performed. The same is true of SED, PGV and velRMs. SAT1 has very good correlation values if each independent building is analyzed. This makes sense due to the period dependence of this IM.

\section{Correlation between IMs}

The correlation between the IMs was determined. For this purpose, a linear correlation using all the available records was performed. The results are shown in Table 6 in a correlation matrix. Strong correlations were found for the pairs CAV-I $\mathrm{I}_{\mathrm{A}}(0.978), \mathrm{CAV}-\mathrm{I}_{\mathrm{C}}(0.89), \mathrm{I}_{\mathrm{A}}-\mathrm{I}_{\mathrm{C}}(0.934), \mathrm{I}_{\mathrm{A}}-\mathrm{SED}(0.856), \mathrm{I}_{\mathrm{C}-}$ accRMS (0.854), ID-PGV-PGV (0.909), ID-PGV-SED (0.878) and accRMS-vel RMS (0.856). The high correlation between the ID-PGV and SED is interesting, since these two IMs have the highest correlations with the MIDR and both are independent from the period of the buildings.

In addition, a correlation analysis was performed for the groups of records (original, scaled and matched). The results are shown in Fig. 8. Here, the square of the linear correlation $\left(\mathrm{R}^{2}\right)$ was used to avoid negative (-) values of correlations. The results obtained with the original records were greater than 
the overall results. The scaled records correlations decreased and a null correlation with the PGA was found, as expected. In the case of the matched records, most correlations decreased significantly, except for $\mathrm{CAV}-\mathrm{I}_{\mathrm{A}}, \mathrm{CAV}-\mathrm{SED}, \mathrm{I}_{\mathrm{A}}-\mathrm{I}_{\mathrm{C}}, \mathrm{I}_{\mathrm{A}}-\mathrm{SED}$ and accRMS-vel $\mathrm{RMS}_{\mathrm{R}}$, for which high correlations were obtained. In Table 7, strong correlations with values $>0.80$ are indicated.

\section{Validation through probabilistic NLDA}

In the first approach, only uncertainties related to seismic action were considered. However, modelling the random variation in building-to-building structural characteristics within a structural typology is standard practice. In this section, we introduce these sources of uncertainties to validate more fully the new intensity measure (ID-PGV). Vargas et al. [43] developed an algorithm that can be used to generate probabilistic multi-degree-of-freedom systems. Although they developed the algorithm for reinforced concrete models, it can easily be adapted to generate structural steel models that are compatible with those analyzed above. The algorithm is a product of the KaIROS project [44], which is focused on maintaining and increasing the resilience and sustainability of communities against earthquakes. Using this algorithm, we generated 500 structural steel models whose number of stories, $N s t$, number of spans, $N s p$, story height, $H s t$, and span length, $S l$, were considered as input random variables. Nst followed a uniform, discrete distribution in the interval $(3,13) ; N v$ also followed a uniform, discrete distribution in the interval $(3,6)$. Hst was distributed uniformly in the interval $(3.3,3.7) \mathrm{m}$. Sl was distributed uniformly in the interval $(5,7) \mathrm{m}$. In order to assign the cross-sectional properties of the structural elements of the first floor, the values presented in Table 8 were adopted. For the upper stories, the size of the columns and beams decreases systematically each 3 stories, to values associated with a building with a lower number of stories. Table 9 presents the main properties of a group of variables that were also considered as random within the analysis. Fig. 9 shows twenty structural models generated by considering the geometrical properties mentioned above. 
One of the main sources of uncertainty in estimations of the seismic risk of structures is the random variability of the ground motion. There are several methodologies to properly select ground motion records that are consistent with the site-dependent spectral shape. However, the main objective of this paper was not to assess the seismic risk of an area, but to develop a simplified procedure for estimating EDPs, like those obtained with NLDAs. With this objective in mind, the most important requirement was to have earthquakes that demand the structural models at different intensity levels. To achieve this, based on the fundamental period range of the generated models, groups of earthquakes were selected whose mean spectral acceleration, in the interval $(0.9-1.3) \mathrm{s}$, was between a band limited by two intensity levels. The intensity levels defining the upper and lower limits of each band range from 0 to 1.5 $\mathrm{g}$ at intervals of $0.15 \mathrm{~g}$. The objective was to obtain 500 records (as many as generated structural models) whereby 50 earthquake records per interval should be found. The database of Ambraseys et al. [45] was used for the earthquake selection. Fig. 10 shows the response spectra of the 500 earthquake records selected according to the described procedure.

Due to the high number of earthquakes requested to fulfil the interval condition, several will be scaled versions of those that naturally meet this condition. Thus, if an interval does not contain 50 earthquake records because there are not enough records in the database, the number of missing records will be selected from the previous interval. This criterion avoids excessive scaling of the earthquake records. After performing the 500 NLDA, the MIDR was correlated with the studied IMs. In Fig. 11 the proposed IM (ID-PGV) is plotted against the MIDR. As this figure shows, ID-PGV maintained a high correlation with the MIDR despite variations in the geometry and mechanical properties of buildings. Table 10 shows a comparison of the new coefficients of determination, from the probabilistic analysis obtained through the first analysis. The new values were consistent with those obtained in the first analysis. Note that the PGA correlation increased considerably in the probabilistic calculation. This is because the bias introduced when scaling the earthquakes to a fixed PGA in the first approach has been eliminated. 
However, in both cases, the PGA exhibited one of the lowest $\mathrm{R}^{2}$ values. The intensity measures that generated the highest correlation were still the PGV, velRms, SED and ID-PGV. Notably, the proposed IM maintained the highest correlation with respect to other intensity measures, in spite of the sources of uncertainties considered. This demonstrates the effectiveness of this intensity measure as an estimator of the potential damage of an earthquake.

\section{Conclusions}

In this study, the destructiveness potential of a group of well-known IMs was analysed. To achieve this, three structural models and a record set including 40 component pairs of horizontal ground motions (80 individual components) were performed. NLDA were performed using the structural models and by scaling and matching the accelerograms of the record set based on different criteria. After performing the NLDA, the MIDRs were calculated for each analysis. The MIDR has been widely used as a good indicator to estimate structural damage due to earthquakes $[46,47]$. This condition is very important because some of the IMs analysed in this article are good predictors of the MIDR. Therefore, the usefulness of the new IM proposed here becomes clear. As the MIDR is highly correlated with the damage, measures that have a high correlation with the MIDR will also be highly correlated with the damage. Thus, the levels of correlation between the MIDR and the IMs were calculated. Based on these results and considering the correlation between the PGV and the significant duration, a new intensity measure that is highly correlated with the MIDR, called ID-PGV, is proposed. ID-PGV works well for the three buildings studied.

The preliminary results indicate that the inter-story height is an important variable to consider in the analysis. In the first part of this study, the inter-story heights were the same for all studied buildings. For this reason, the building-to-building structural characteristic variations were considered through probabilistic NLDA and therefore the use of the proposed IM, ID-PGV, was validated. A total of 500 NLDA 
were performed, varying the geometry and mechanical properties of the building models. The results validate those obtained using the first approach and therefore confirm the effectiveness of the proposed IM.

Only two-dimension symmetrical buildings were analysed in this study. Further analyses should be performed with other structural typologies, three-dimensional and non-symmetrical building models, to validate the general performance. The coefficients $\alpha$ and $\beta$, presented in Equation 7 , should be recalibrated when other building typologies are analysed. If this measure could be validated for different structural typologies, it would be effective to perform seismic hazard and risk analyses. In addition, the earthquake-resistant design approach used in this study protects the structures against failures due to second order effects. Thus, future research studies should be carried out to analyze the evolution of $\alpha$ and $\beta$ coefficients by considering different types of design conditions.

Finally, one of the main advantages of ID-PGV is that it is independent of the building period. In future research, the potential of the proposed IM should be compared with other IMs that consider the structural behaviour through the period elongation of buildings [48-52].

\section{Acknowledgements}

This research was partially funded by the Spanish Government's Ministry of Economy and Competitiveness (MINECO) and by the European Regional Development Fund (ERDF) of the European Union (EU) through the project referenced as CGL2015-65913-P (MINECO/ERDF, EU). Luis A. Pinzón is supported by a Ph.D. scholarship grant from the Government of Panama's Institute for the Training and Development of Human Resources (IFARHU) and the National Secretariat of Science, Technology, and Innovation (SENACYT). Yeudy F. Vargas-Alzate has been granted an Individual Fellowship (IF) in the research grant programme of the Marie Sklodowska-Curie Actions (MSCA) of the European Union/European (H2020-MSCA-IF-2017), No 799553. 


\section{References}

[1] National Geophysical Data Center / World Data Service (NGDC/WDS). Significant Earthquake Database. National Geophysical Data Center, NOAA. n.d. doi:10.7289/V5TD9V7K.

[2] DesRoches R, Comerio M, Eberhard M, Mooney W, Rix GJ. Overview of the 2010 Haiti earthquake. Earthq Spectra 2011;27:1-21. doi:10.1193/1.3630129.

[3] Biot M. A Mechanical Analyzer for the Prediction of Earthquake Stresses. Bull Seismol Soc Am $1941 ; 31: 151-71$.

[4] Biot M. Theory of Elastic Systems Vibrating Under Transient Impulse with an Application to Earthquake - Proof Buildings. Proc. Natl. Acad. Sci., vol. 19, 1933, p. 262-8.

[5] Biot M. Analytical and Experimental Methods in Engineering Seismology. Trans Am Soc Am $1943 ; 108: 365-85$.

[6] Pacor F, Paolucci R, Ameri G, Massa M, Puglia R. Italian strong motion records in ITACA: Overview and record processing. Bull Earthq Eng 2011;9:1741-59. doi:10.1007/s10518-0119295-x.

[7] Park Y, Ang AH -S. Mechanistic Seismic Damage Model for Reinforced Concrete. J Struct Eng 1985;111:722-39. doi:10.1061/(ASCE)0733-9445(1985)111:4(722).

[8] de Lautour OR, Omenzetter P. Prediction of seismic-induced structural damage using artificial neural networks. Eng Struct 2009;31:600-6. doi:10.1016/j.engstruct.2008.11.010.

[9] Morfidis K, Kostinakis K. Seismic parameters' combinations for the optimum prediction of the damage state of R/C buildings using neural networks. Adv Eng Softw 2017;106:1-16. doi:10.1016/j.advengsoft.2017.01.001.

[10] Douglas J. Ground motion prediction equations 1964-2016. Glasgow, UK: 2017. 
[11] Kostinakis KG, Athanatopoulou AM, Morfidis K. Correlation between ground motion intensity measures and seismic damage of 3D R/C buildings. Eng Struct 2015;82:151-67. doi:10.1016/j.engstruct.2014.10.035.

[12] Garini E, Gazetas G. Damage potential of near-fault records: Sliding displacement against conventional “Intensity Measures.” Bull Earthq Eng 2013;11:455-80. doi:10.1007/s10518-0129397-0.

[13] Benioff H. The physical evaluation of seismic destructiveness. Bull Seismol Soc Am 1934:398403.

[14] Arias A. A measure of earthquake intensity. Cambridge, MA, MIT Press 1970:438-83.

[15] Husid LR. Características de terremotos. Análisis general. Rev Del IDIEM 1969;8:21-42.

[16] Bolt BA. Duration of strong ground motion. 5th World Conf. Earthq. Eng., vol. 1, 1973, p. 130413.

[17] Housner GW. Measures of severity of earthquake ground shaking. Proc. U.S. Natl. Conf. Earthq. Eng., 1975, p. 25-33.

[18] Trifunac MD, Brady AG. A study on the duration of strong earthquake ground motion. Bull Seismol Soc Am 1975;65:581-626.

[19] Bommer JJ, Martínez-Pereira A. The effective duration of earthquake strong motion. J Earthq Eng 1999;3:127-72. doi:10.1080/13632469909350343.

[20] Dobry R, Idriss IM, Ng E. Duration characteristics of horizontal components of strong-motion earthquake records. Bull Seismol Soc Am 1978;68:1487-520.

[21] Sarma SK, Yang KS. An evaluation of strong motion records and a new parameter A95. Earthq Eng Struct Dyn 1987;15:119-32. doi:10.1002/eqe.4290150109. 
[22] Sarma SK. Energy flux of strong earthquakes. Tectonophysics 1971;11:159-72.

[23] Park YJ, Ang AHS, Wen YK. Damage-Limiting Aseismic Design of Buildings. Earthq Spectra 1987;3:1-26. doi:10.1193/1.1585416.

[24] Reed JW, Kassawara RP. A criterion for determining exceedance of the Operating Basis Earthquake. Nucl Eng Des 1990;123:387-96.

[25] Elenas A. Correlation between seismic acceleration parameters and overall structural damage indices of buildings. Soil Dyn Earthq Eng 2000;20:93-100.

[26] Hancock J, Bommer JJ. A State-of-Knowledge Review of the Influence of Strong-Motion Duration on Structural Damage. Earthq Spectra 2006;22:827-45. doi:10.1193/1.2220576.

[27] Muin S, Mosalam KM. Cumulative Absolute Velocity as a Local Damage Indicator of Instrumented Structures. Earthq Spectra 2017;33:641-64. doi:10.1193/090416EQS142M.

[28] Federal Emergency Management Agency (FEMA). HAZUS'99 (SR 2) technical manual. Federal Emergency Management Agency, Washington, DC: 2002.

[29] ASTM A992 / A992M - 11. Standard Specification for Structural Steel Shapes. 2015.

[30] ANSI/AISC 358-10. Prequalified connections for special and intermediate steel moment frames for seismic applications. 2010.

[31] ANSI/AISC 341-10. Seismic Provisions for Structural Steel Buildings. 2010.

[32] ASCE. Minimum Design Loads for Buildings and Other Structures. 2010. doi:10.1061/9780784412916.

[33] Carr AJ. Ruaumoko 2D and 3D - Inelastic Dynamic Analysis Program 2002.

[34] Ibarra LF, Medina RA, Krawinkler H. Hysteretic models that incorporate strength and stiffness deterioration. Earthq Eng Struct Dyn 2005;34:1489-511. doi:10.1002/eqe.495. 
[35] Lignos DG, Krawinkler H. Deterioration Modeling of Steel Components in Support of Collapse Prediction of Steel Moment Frames under Earthquake Loading. J Struct Eng 2011;137:1291-302. doi:10.1061/(ASCE)ST.1943-541X.0000376.

[36] Lignos DG, Krawinkler H. Development and Utilization of Structural Component Databases for Performance-Based Earthquake Engineering. J Struct Eng 2013;139:1382-94. doi:10.1061/(ASCE)ST.1943-541X.0000646.

[37] Diaz SA, Pujades LG, Barbat AH, Hidalgo-Leiva DA, Vargas-Alzate YF. Capacity, damage and fragility models for steel buildings: a probabilistic approach. vol. 16. 2018. doi:10.1007/s10518017-0237-0.

[38] CEN. European Standard EN 1998-1:2005 Eurocode 8: Design of structures for earthquake resistance. Part 1: General rules, seismic actions and rules for buildings English version. Brussels, Belgium: 2004.

[39] Pinzón LA, Diaz SA, Pujades LG, Vargas YF. An efficient method for considering the directionality effect of earthquakes on structures. J Earthq Eng 2019;in-press:1-30. doi:10.1080/13632469.2019.1597783.

[40] Diaz SA, Pujades LG, Barbat AH, Vargas YF, Hidalgo-Leiva DA. Energy damage index based on capacity and response spectra. Eng Struct 2017;152:424-36. doi:10.1016/j.engstruct.2017.09.019.

[41] The MathWorks. MATLAB and Statistics Toolbox Release 2016b,The MathWorks, Inc.,Natick, Massachusetts, United States. 2017.

[42] Seismosoft. SeismoSignal - A computer program for signal processing of time-histories 2018.

[43] Vargas YF, Pujades LG, González-Drigo JR, Alva RE, Pinzón LA. ON THE EQUAL DISPLACEMENT APROXIMATION FOR MID-RISE REINFORCED CONCRETE 
BUILDINGS. COMPDYN 2019 7th Int. Conf. Comput. Methods Struct. Dyn. Earthq. Eng., 2019.

[44] Vargas-Alzate YF. KaIROS Project. Keeping and Increasing Resilience Opportunities and Sustainability of communities against earthquakes. https://cordis.europa.eu/project/rcn/215743/factsheet/en 2018.

[45] Ambraseys NN, Smit PM, Beradi R, Rinaldis D, Cotton F, Berge C. Dissemination of European Strong-Motion Data, CD ROM collection, European Commission, Directorate-General XII, Environmental and Climate Programme, ENV4-CT97-0397. 2000.

[46] Ghobarah A, Abou-Elfath H, Biddah A. Response-based damage assessment of structures. Earthq Eng Struct Dyn 1999;28:79-104. doi:10.1002/(SICI)1096-9845(199901)28:1<79::AIDEQE805>3.0.CO;2-J.

[47] Raghunandan M, Liel AB, Luco N. Aftershock collapse vulnerability assessment of reinforced concrete frame structures. Earthq Eng Struct Dyn 2015;44:419-39. doi:10.1002/eqe.2478 Aftershock.

[48] Theophilou AAI, Chryssanthopoulos MK, Kappos AJ. A vector-valued ground motion intensity measure incorporating normalized spectral area. Bull Earthq Eng 2017;15:249-70. doi:10.1007/s10518-016-9959-7.

[49] Zhou Y, Li M. An area-based intensity measure for incremental dynamic analysis. J Asian Archit Build Eng 2015;14:451-7. doi:10.3130/jaabe.14.451.

[50] Kohrangi M, Bazzurro P, Vamvatsikos D, Spillatura A. Conditional spectrum-based ground motion record selection using average spectral acceleration. Earthq Eng Struct Dyn 2017;46:1667-85. doi:10.1002/eqe.2876.

[51] Bojórquez E, Chávez R, Reyes-Salazar A, Ruiz SE, Bojórquez J. A new ground motion intensity measure IB. Soil Dyn Earthq Eng 2017;99:97-107. doi:10.1016/j.soildyn.2017.05.011. 
[52] Bojórquez E, Iervolino I. Spectral shape proxies and nonlinear structural response. Soil Dyn Earthq Eng 2011;31:996-1008. doi:10.1016/j.soildyn.2011.03.006. 


\section{Figures}

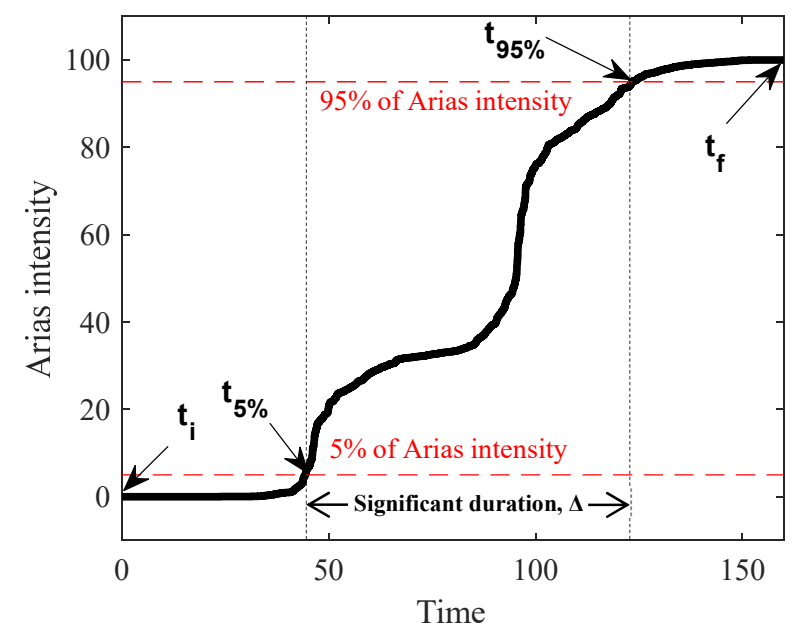

Fig. 1. Definition of the significant duration of a single accelerograms using the Husid plot [15] [accumulative energy (\%) in terms of Arias intensity vs. time (s)].
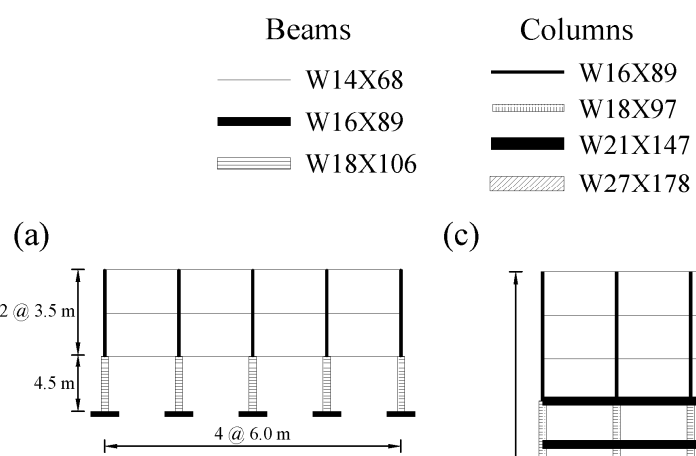

(c)

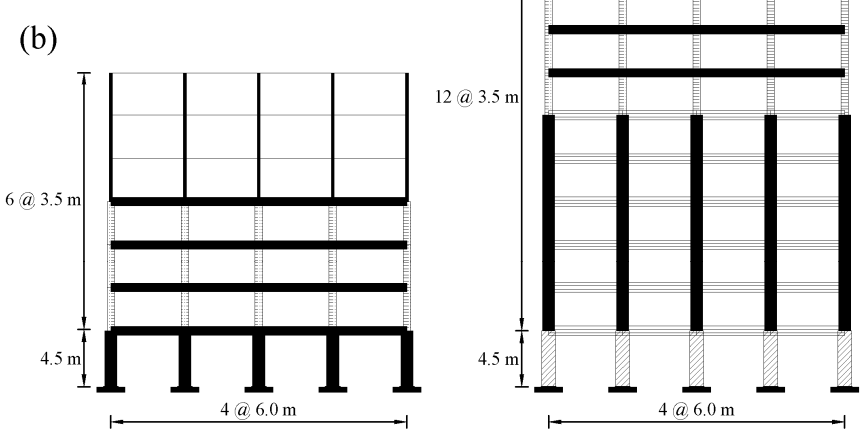

Fig. 2. Steel moment frame model dimensions for (a) 3-story, (b) 7-story and (c) 13-story buildings. 


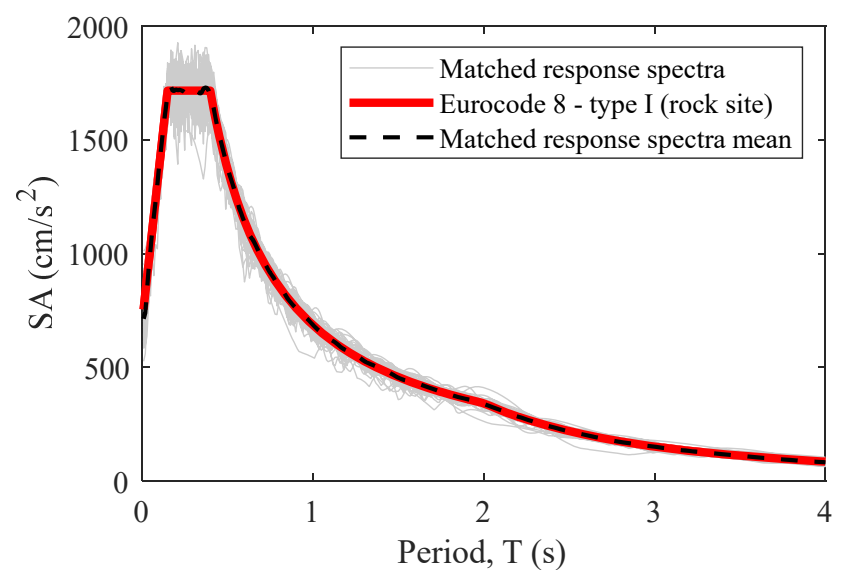

Fig. 3. Five per cent damped response spectra, corresponding to the 80 selected accelerograms, matched to the design spectrum of Eurocode 8 for earthquakes with $\mathbf{M}>5.5$ (type I) located in rock (site A). (For an interpretation of the references to colour in this figure, the reader is referred to the web version of this article). 

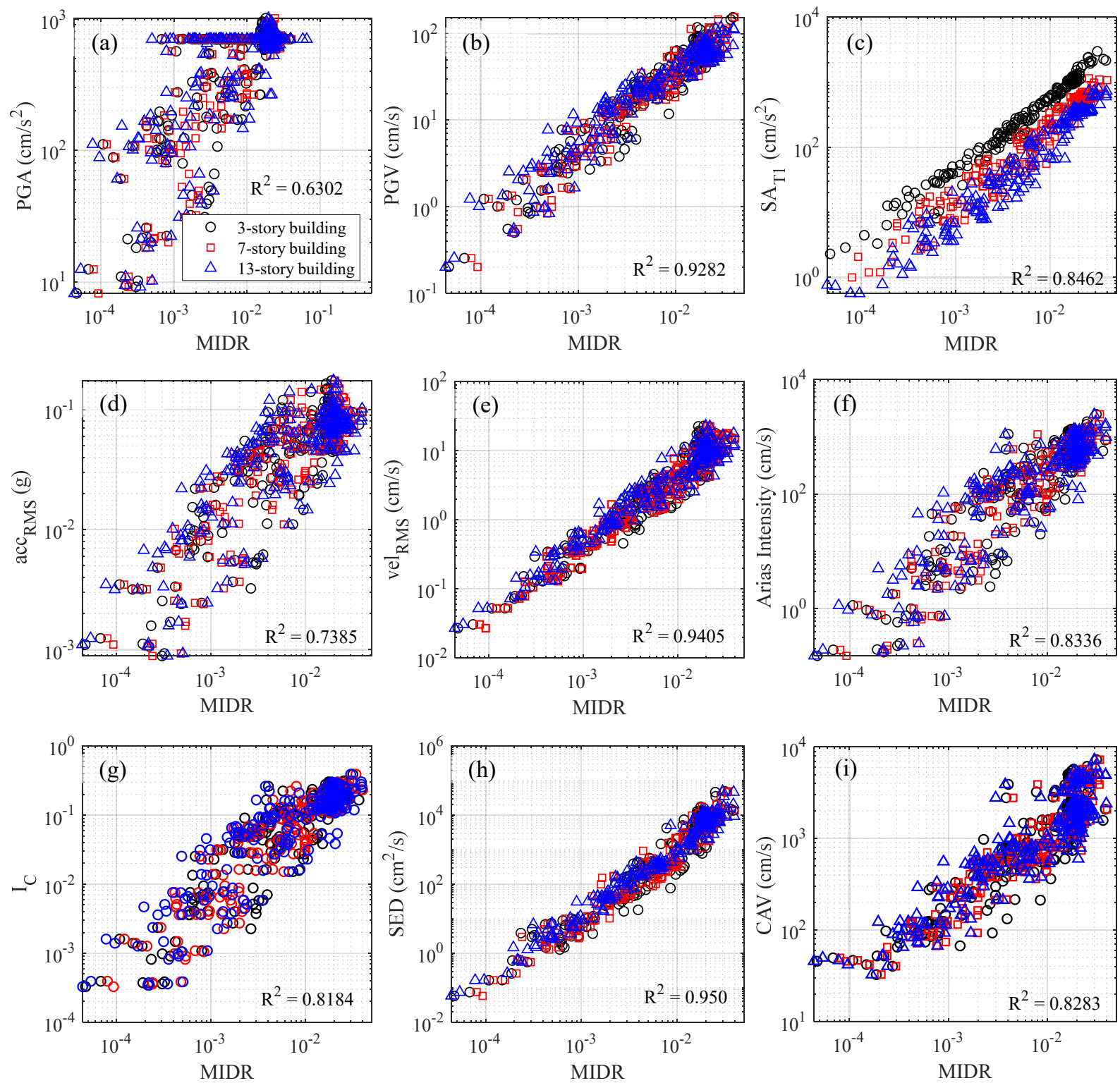

Fig. 4. Correlation between the maximum drift and several intensity measures: (a) PGA, (b) PGV, (c) $\mathrm{SA}_{\mathrm{T} 1}$, (d) acc $\mathrm{R}_{\mathrm{RMS}}$, (e) vel $_{\text {RMS }}$, (f) Arias intensity, (g) Characteristic intensity, (h) Specific Energy Density and (i) Cumulative Absolute Velocity. 

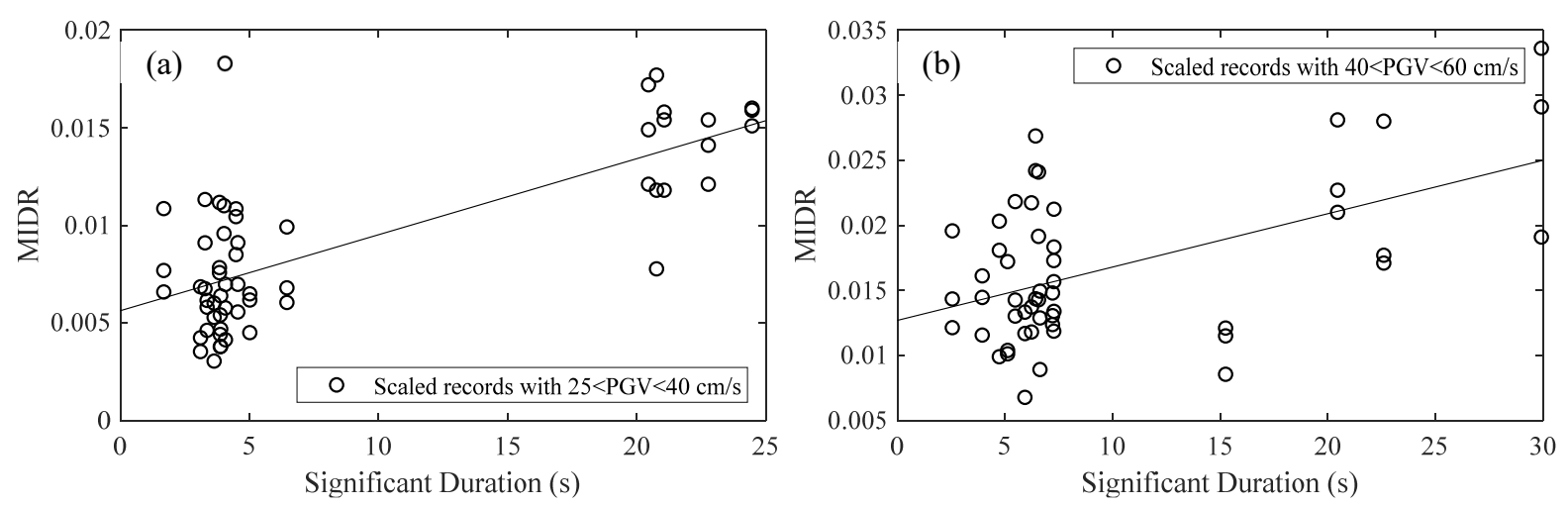

Fig. 5. Influence of duration on the maximum drift for scaled accelerograms and ranges of $\mathrm{PGV}$ : (a) $25<\mathrm{PGV}<40 \mathrm{~cm} / \mathrm{s}$ and (b) $40<\mathrm{PGV}<60 \mathrm{~cm} / \mathrm{s}$.
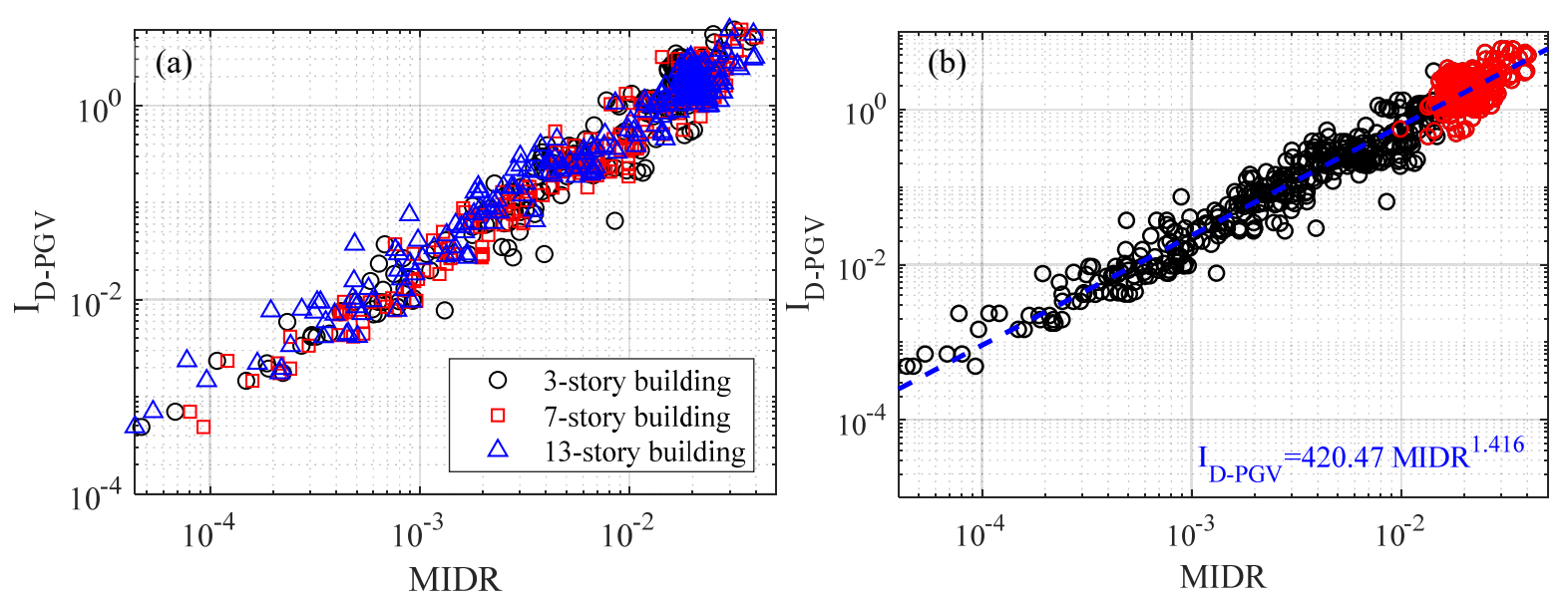

Fig. 6. (a) Comparison between the maximum drift and the proposed intensity measure $\mathrm{I}_{\mathrm{D}-\mathrm{PGV}}$. (b) In red, damaged buildings (with DI > 0.1) and in black, buildings that did not suffer damage. (For an interpretation of the references to colour in this figure, the reader is referred to the web version of this article). 


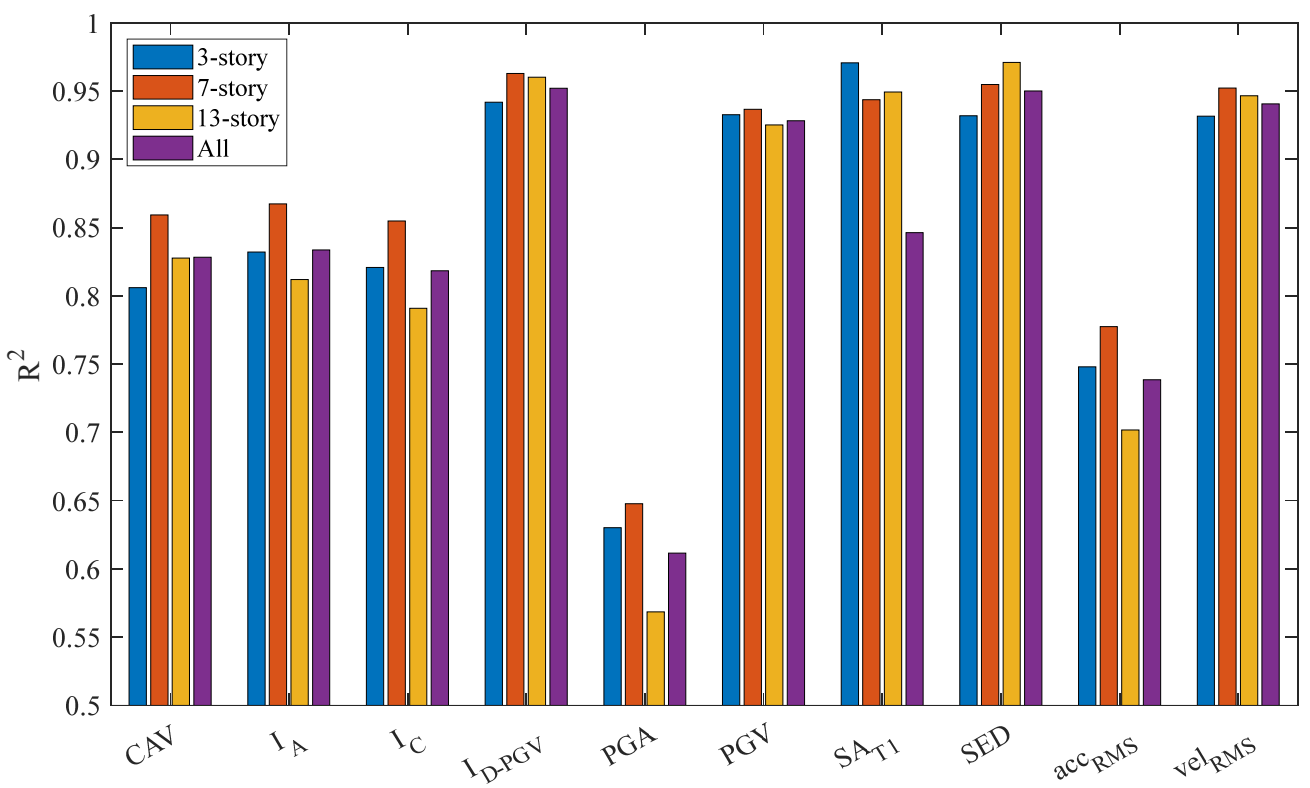

Fig. 7. Coefficient of determination $\left(\mathrm{R}^{2}\right)$ for the comparison of different IMs with the MIDR drift corresponding to the results obtained by performing the NLDAs for the 3-story building, 7-story building, 13-story building and all the buildings. 
a)

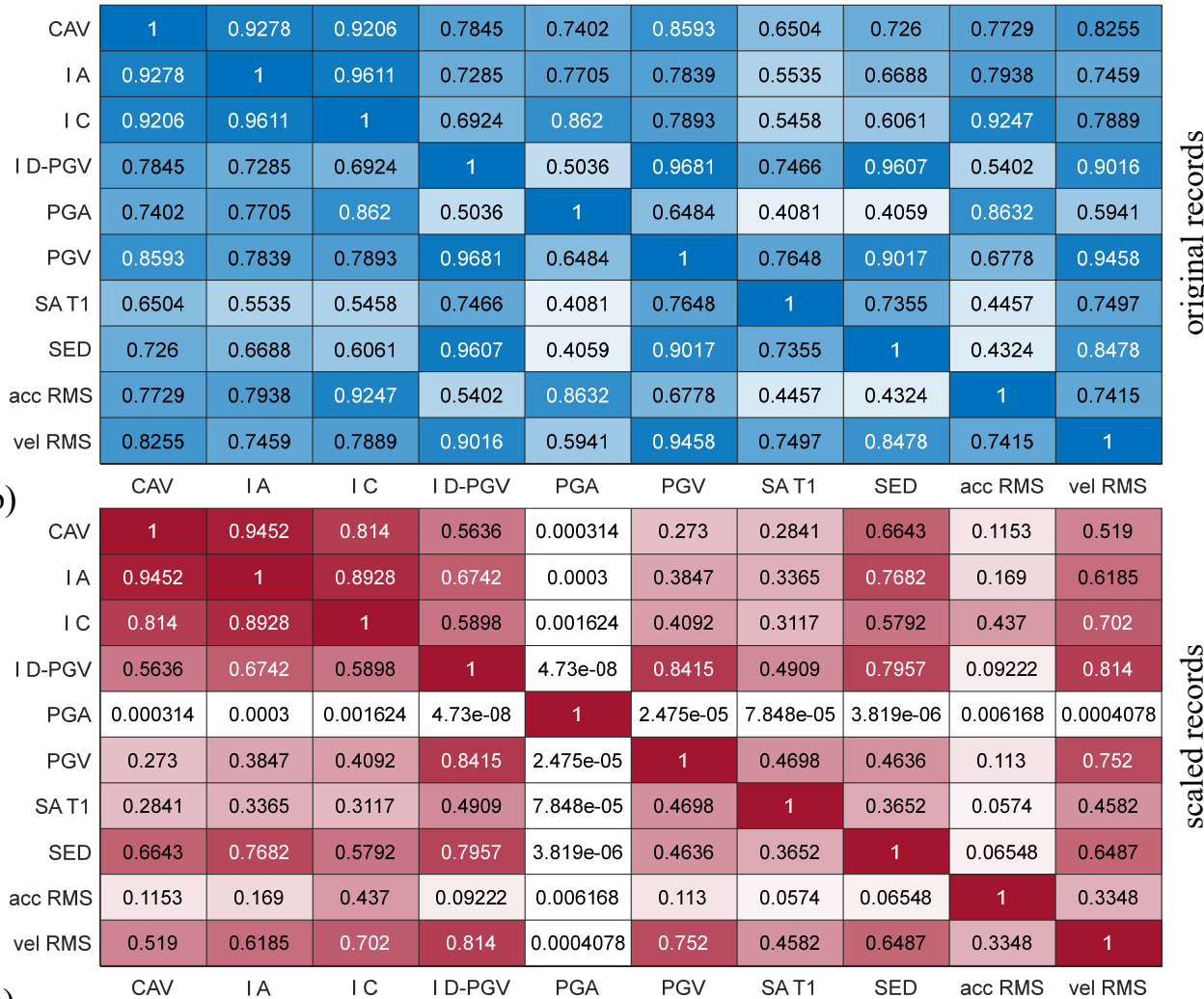

\begin{tabular}{|c|c|c|c|c|c|c|c|c|c|c|}
\hline & CAV & IA & IC & I D-PGV & PGA & PGV & SAT1 & SED & acc RMS & vel RMS \\
\hline CAV & 1 & 0.9524 & 0.5606 & 0.2086 & 0.2836 & 0.2355 & $4.33 \mathrm{e}-09$ & 0.8812 & 0.02784 & 0.1533 \\
\hline IA & 0.9524 & 1 & 0.7274 & 0.1528 & 0.3158 & 0.2303 & $7.127 \mathrm{e}-06$ & 0.7884 & 0.0002858 & 0.08077 \\
\hline IC & 0.5606 & 0.7274 & 1 & 0.08249 & 0.2307 & 0.157 & $1.983 \mathrm{e}-05$ & 0.4068 & 0.2384 & 0.04313 \\
\hline I D-PGV & 0.2086 & 0.1528 & 0.08249 & 1 & 0.002372 & 0.1847 & $6.183 \mathrm{e}-06$ & 0.2179 & 0.005968 & 0.008807 \\
\hline PGA & 0.2836 & 0.3158 & 0.2307 & 0.002372 & 1 & 0.24 & $3.798 \mathrm{e}-05$ & 0.2431 & 0.0009484 & 0.04877 \\
\hline PGV & 0.2355 & 0.2303 & 0.157 & 0.1847 & 0.24 & 1 & $3.069 \mathrm{e}-05$ & 0.1954 & 0.007714 & 0.05527 \\
\hline SAT1 & $4.33 \mathrm{e}-09$ & $7.127 \mathrm{e}-06$ & $1.983 \mathrm{e}-05$ & $6.183 \mathrm{e}-06$ & $3.798 \mathrm{e}-05$ & $3.069 \mathrm{e}-05$ & 1 & $8.742 \mathrm{e}-07$ & $1.092 \mathrm{e}-05$ & $2.911 \mathrm{e}-06$ \\
\hline SED & 0.8812 & 0.7884 & 0.4068 & 0.2179 & 0.2431 & 0.1954 & $8.742 \mathrm{e}-07$ & 1 & 0.0513 & 0.1275 \\
\hline acc RMS & 0.02784 & 0.0002858 & 0.2384 & 0.005968 & 0.0009484 & 0.007714 & $1.092 \mathrm{e}-05$ & 0.0513 & 1 & 0.8605 \\
\hline vel RMS & 0.1533 & 0.08077 & 0.04313 & 0.008807 & 0.04877 & 0.05527 & $2.911 \mathrm{e}-06$ & 0.1275 & 0.8605 & 1 \\
\hline
\end{tabular}

Fig. 8. Matrices of $\mathrm{R}^{2}$ from the correlation between the IMs used in this study for the (a) original records, (b) scaled records and (c) the matched records. 


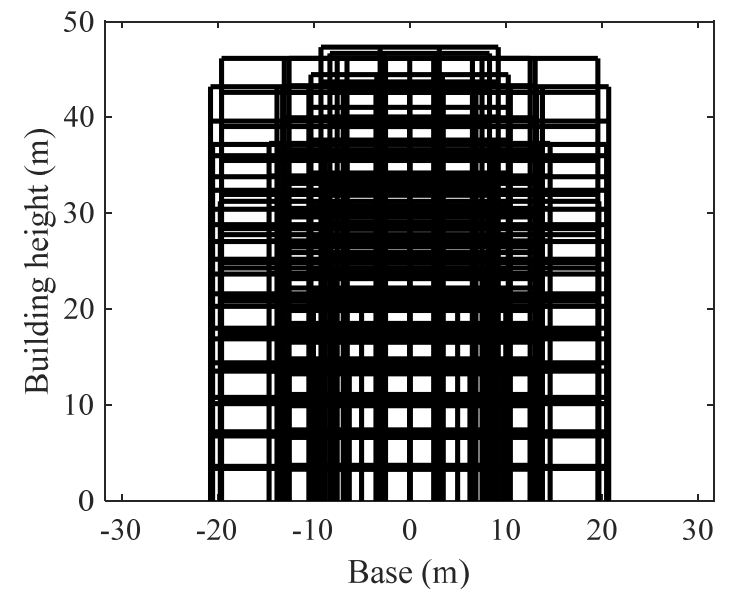

Fig. 9. Twenty 2-D steel-frame building models.

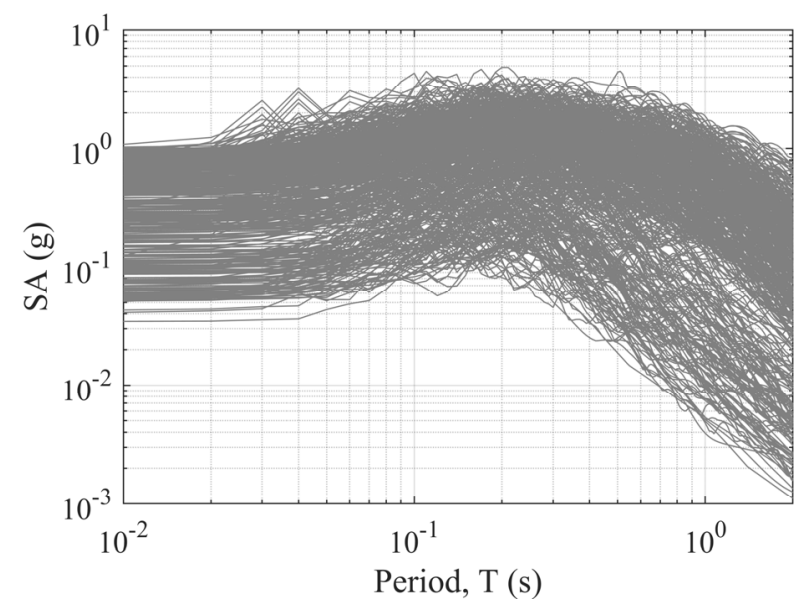

Fig. 10. Response spectra of the selected ground motion records for the probabilistic analysis.

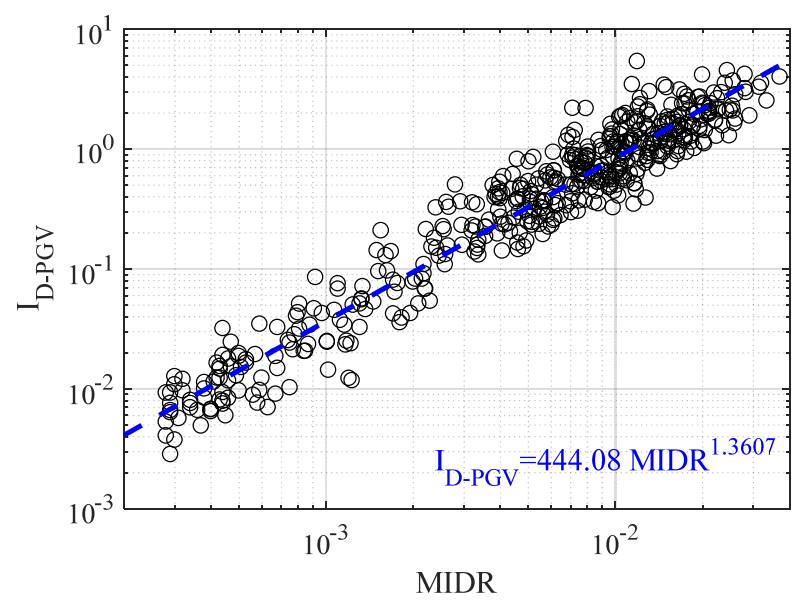

Fig. 11. Results after performing the 500 NLDA. Relation between the MIDR and the proposed intensity measure $\mathrm{I}_{\mathrm{D}-\mathrm{PGV}}$. 
Tables

Table 1. List of intensity measures used in this study (see also explanation in the text).

\begin{tabular}{|c|c|c|c|}
\hline Intensity measure & Acronym & Formulation & Units \\
\hline Arias intensity & $\mathrm{I}_{\mathrm{A}}$ & $\frac{\pi}{2 g} \int_{t_{i}}^{t_{f}} a(t)^{2} d t$ & $\mathrm{~cm} / \mathrm{s}$ \\
\hline Root mean square (RMS) of acceleration & accerMS & $\sqrt{\frac{1}{\Delta} \int_{t_{5 \%}}^{t_{95 \%}} a(t)^{2} d t}$ & g \\
\hline Root mean square (RMS) of velocity & vel $_{\text {RMS }}$ & $\sqrt{\frac{1}{\Delta} \int_{t_{5 \%}}^{t_{95 \%}} v(t)^{2} d t}$ & $\mathrm{~cm} / \mathrm{s}$ \\
\hline Specific energy density & SED & $\int_{t_{i}}^{t_{f}} v(t)^{2} d t$ & $\mathrm{~cm}^{2} / \mathrm{s}$ \\
\hline Characteristic intensity & $\mathrm{I}_{\mathrm{C}}$ & $\operatorname{acc}_{R M S}{ }^{1.5} \sqrt{t_{f}}$ & - \\
\hline Cumulative absolute velocity & CAV & $\int_{t_{i}}^{t_{f}}|a(t)| d t$ & $\mathrm{~cm} / \mathrm{s}$ \\
\hline Peak ground acceleration & PGA & $\max |a(t)|$ & $\mathrm{cm} / \mathrm{s}^{2}$ \\
\hline Peak ground velocity & PGV & $\max |v(t)|$ & $\mathrm{cm} / \mathrm{s}$ \\
\hline Spectral acceleration for the fundamental period & SAT1 & $\max \left|\ddot{u}\left(T_{1}, \xi\right)\right|$ & $\mathrm{cm} / \mathrm{s}^{2}$ \\
\hline
\end{tabular}

* $\ddot{u}$ is the linear response of a SDOF vibrating system in terms of acceleration with a fundamental period $\left(\mathrm{T}_{1}\right)$ and with a critical damping $(\xi)$. 
Table 2. Ground motions selection from the ITACA database.

\begin{tabular}{|c|c|c|c|c|c|c|c|c|c|c|}
\hline \multirow{2}{*}{ Event id $^{(1)}$} & \multirow{2}{*}{ Date and time } & \multirow{2}{*}{ Station $^{(2)}$} & \multirow{2}{*}{$\mathbf{M} \mathbf{w}^{(3)}$} & \multirow{2}{*}{$\begin{array}{c}\text { Site } \\
\text { EC }^{(4)}\end{array}$} & \multirow{2}{*}{$\begin{array}{c}\text { Epi. } \\
(\mathbf{k m})^{(5)}\end{array}$} & \multicolumn{2}{|c|}{ PGA $\left(\mathbf{c m} / \mathbf{s}^{\mathbf{2}}\right)^{(6)}$} & \multirow{2}{*}{$\begin{array}{c}\text { Eff. dur. } \\
\text { (s) }^{(7)}\end{array}$} & \multicolumn{2}{|c|}{ Sig. dur., $\Delta(\mathbf{s})^{(8)}$} \\
\hline & & & & & & E-W & N-S & & E-W & $\mathbf{N}-\mathbf{S}$ \\
\hline EMSC-20161027_0000072 & 25/08/16 3:17 AM & $N R C A$ & 4.3 & $B$ & 4.6 & 100.9 & 122.0 & 3.8 & 3.8 & 3.1 \\
\hline IT-2009-0095 & 07/04/09 9:26 AM & $A Q V$ & 5.1 & $B$ & 5.8 & 184.5 & 96.2 & 3.8 & 2.6 & 3.7 \\
\hline$I T-1998-0054$ & 03/04/98 7:26 AM & NOCE & 5.1 & $B$ & 6.4 & 276.4 & 566.8 & 3.9 & 3.9 & 2.1 \\
\hline$I T-2012-0033$ & $31 / 05 / 122: 58 P M$ & T0826 & 3.7 & $C$ & 5.8 & 60.7 & 107.1 & 3.9 & 2.0 & 1.3 \\
\hline$I T-1976-0024$ & 11/09/76 4:31 PM & $G M N$ & 5.2 & $B$ & 6.1 & 152.0 & 186.8 & 3.9 & 3.3 & 3.9 \\
\hline$I T-2009-0140$ & 09/04/09 7:38 PM & $R M 11$ & 5.2 & $B$ & 7.1 & 165.8 & 166.5 & 4.0 & 3.0 & 2.0 \\
\hline IT-2009-0105 & 07/04/09 9:34 PM & RM07 & 4.5 & $B$ & 4.5 & 171.6 & 106.8 & 4.0 & 2.6 & 4.0 \\
\hline IT-1977-0008 & 16/09/77 11:48 PM & $S M U$ & 5.3 & $B$ & 7.1 & 79.5 & 179.4 & 4.0 & 3.1 & 1.7 \\
\hline IT-2005-0145 & 08/11/05 9:10 PM & $C S N$ & $3.6^{*}$ & $B$ & 1.9 & 88.3 & 111.1 & 4.1 & 2.1 & 3.0 \\
\hline EMSC-20160824_0000050 & 24/08/16 4:06 AM & $N R C A$ & 4.4 & $B$ & 7.0 & 123.8 & 153.1 & 4.1 & 4.1 & 3.6 \\
\hline IT-1997-0163 & 19/10/97 4:00 PM & CESV & 4.2 & $\mathrm{C}$ & 4.5 & 101.2 & 141.9 & 4.9 & 3.4 & 3.2 \\
\hline IT-1976-0024 & 11/09/76 4:31 PM & FRC & 5.2 & B & 16.6 & 109.7 & 95.0 & 4.9 & 4.8 & 4.6 \\
\hline EMSC-20170118_0000119 & 18/01/17 1:33 PM & MSC & 5.0 & B & 8.0 & 123.4 & 153.9 & 5.0 & 3.8 & 3.9 \\
\hline EMSC-20161026_0000133 & 26/10/16 9:42 PM & CLO & 4.5 & A & 7.9 & 96.1 & 84.5 & 5.0 & 3.1 & 5.0 \\
\hline IT-2009-0102 & 07/04/09 5:47 PM & MI05 & 5.5 & A & 3.6 & 651.5 & 304.1 & 5.0 & 3.6 & 5.0 \\
\hline IT-2010-0032 & 16/08/10 12:54 PM & ILLI & 4.7 & A & 11.4 & 323.0 & 382.2 & 5.1 & 5.1 & 4.7 \\
\hline EMSC-20161026_0000095 & 26/10/16 7:18 PM & $\mathrm{CNE}$ & 5.9 & $\mathrm{C}$ & 2.5 & 527.0 & 373.1 & 5.2 & 4.5 & 5.2 \\
\hline EMSC-20161026_0000095 & 26/10/16 7:18 PM & $\mathrm{MCV}$ & 5.9 & $\mathrm{~B}$ & 14 & 377.2 & 538.8 & 5.4 & 5.2 & 4.3 \\
\hline IT-1997-0004 & 26/09/97 12:33 AM & CLF & 5.7 & $\mathrm{D}$ & 2.8 & 251.7 & 271.4 & 5.5 & 5.2 & 5.5 \\
\hline IT-1997-0004 & 26/09/97 12:33 AM & NCR & 5.7 & $\mathrm{E}$ & 13.2 & 250.9 & 387.4 & 5.5 & 4.1 & 5.5 \\
\hline EMSC-20161026_0000077 & 26/10/16 5:10 PM & $C N E$ & 5.4 & $C$ & 2.6 & 545.6 & 219.5 & 6.5 & 3.9 & 6.5 \\
\hline IT-2012-0011 & 29/05/12 7:00 AM & T0813 & 6.0 & $C$ & 11.3 & 361.2 & 331.9 & 6.6 & 5.9 & 6.6 \\
\hline EMSC-20161030_0000029 & 30/10/16 6:40 AM & $T 1214$ & 6.5 & $B$ & 11.4 & 593.2 & 413.0 & 6.8 & 6.8 & 6.4 \\
\hline IT-2012-0011 & 29/05/12 7:00 AM & SANO & 6.0 & $C$ & 6.1 & 170.9 & 216.7 & 6.8 & 6.7 & 6.8 \\
\hline EMSC-20161026_0000077 & 26/10/16 5:10 PM & $F O C$ & 5.4 & $C$ & 24.9 & 331.2 & 196.8 & 6.9 & 3.9 & 5.6 \\
\hline IT-2012-0011 & 29/05/12 7:00 AM & MIRE & 6.0 & $C$ & 4.1 & 173.3 & 265.5 & 7.1 & 7.1 & 6.9 \\
\hline IT-2012-0011 & 29/05/12 7:00 AM & $M I R H$ & 6.0 & $C$ & 4.5 & 146.8 & 265.0 & 7.1 & 7.1 & 6.7 \\
\hline$I T-2012-0011$ & 29/05/12 7:00 AM & MIRO1 & 6.0 & $C$ & 0.5 & 411.4 & 373.0 & 7.2 & 6.6 & 7.2 \\
\hline IT-2012-0011 & 29/05/12 7:00 AM & T0802 & 6.0 & $C$ & 9.9 & 258.8 & 290.7 & 7.3 & 7.3 & 7.2 \\
\hline IT-2012-0011 & 29/05/12 7:00 AM & T0800 & 6.0 & $C$ & 14.4 & 330.6 & 248.9 & 7.3 & 6.2 & 7.3 \\
\hline IT-2012-0010 & $29 / 05 / 12$ 10:55 AM & MIR07 & 5.5 & $\mathrm{C}$ & 26.8 & 31.0 & 32.1 & 29.7 & 21.3 & 23.0 \\
\hline EMSC-20170118_0000037 & 18/01/17 10:25 AM & $\mathrm{CNO}$ & 5.4 & B & 74.4 & 9.4 & 10.9 & 29.8 & 24.5 & 22.8 \\
\hline EMSC-20161026_0000077 & 26/10/16 5:10 PM & MNTP & 5.4 & $\mathrm{~B}$ & 39.9 & 21.5 & 21.1 & 29.9 & 20.5 & 20.8 \\
\hline IT-2012-0008 & 20/05/12 2:03 AM & MLD & 6.1 & $\mathrm{C}$ & 107.6 & 22.2 & 19.9 & 29.9 & 20.5 & 22.6 \\
\hline EMSC-20160824_0000006 & 24/08/16 1:36 AM & SRL & 6.0 & $\mathrm{C}$ & 96.3 & 18.1 & 25.7 & 29.9 & 21.1 & 15.3 \\
\hline EMSC-20161026_0000095 & 26/10/16 7:18 PM & ATFO & 5.9 & $\mathrm{~B}$ & 68.1 & 10.2 & 9.1 & 29.9 & 29.9 & 26.4 \\
\hline EMSC-20160824_0000006 & 24/08/16 1:36 AM & BVG & 6.0 & $\mathrm{C}$ & 57.2 & 39.1 & 49.2 & 30.2 & 29.8 & 28.7 \\
\hline IT-2006- $02 \overline{2} 2$ & 26/10/06 2:28 PM & VBV & 5.8 & $\mathrm{~B}$ & 53.3 & 12.4 & 8.2 & 30.2 & 30.2 & 29.5 \\
\hline EMSC-20161026_0000095 & 26/10/16 7:18 PM & IT.SNG & 5.9 & $\mathrm{C}$ & 86.7 & 45.5 & 52.7 & 30.6 & 22.7 & 25.6 \\
\hline IT-2012-0011 & 29/05/12 7:00 AM & CASO & 6.0 & $\mathrm{C}$ & 28.1 & 66.2 & 42.0 & 30.7 & 18.2 & 19.7 \\
\hline
\end{tabular}

\footnotetext{
(1) Event identification code from the ITACA database.

(2) Accelerometric station code.

Moment magnitude.

Site condition following the Eurocode 8 specifications.

Epicentral distance in $\mathrm{km}$.

Peak ground acceleration for the horizontal components (E-W and N-S)

Effective duration in seconds provided in the ITACA database.

Estimated significant duration in seconds.

* Value estimated with local magnitude $\left(\mathrm{M}_{\mathrm{L}}\right)$
} 
Table 3. $\mathrm{R}^{2}$ value obtained from the correlation of each IM with the MIDR.

\begin{tabular}{cccccccccc}
\hline Records & PGA & PGV & SA $_{\text {T1 }}$ & $\mathbf{a c c}_{\text {RMS }}$ & vel $_{\text {RMS }}$ & $\mathbf{I}_{\mathbf{A}}$ & $\mathbf{I}_{\mathbf{C}}$ & SED & CAV \\
\hline Original & 0.469 & 0.895 & 0.807 & 0.614 & 0.924 & 0.759 & 0.722 & 0.929 & 0.825 \\
Scaled & 0.008 & 0.865 & 0.749 & 0.361 & 0.870 & 0.692 & 0.686 & 0.887 & 0.591 \\
Matched & 0.016 & 0.011 & 0.285 & 0.003 & 0.000 & 0.031 & 0.030 & 0.022 & 0.024 \\
Original + Scaled & 0.546 & 0.916 & 0.822 & 0.682 & 0.938 & 0.796 & 0.771 & 0.939 & 0.816 \\
All & 0.630 & 0.928 & 0.846 & 0.739 & 0.941 & 0.834 & 0.818 & 0.950 & 0.828 \\
\hline
\end{tabular}

Table 4. Equation and coefficients used in the minimization (720 NLDA).

Equation

\begin{tabular}{cccccccccc} 
IM & PGA & PGV & SA $_{T 1}$ & acc $_{\text {RMS }}$ & vel $_{\text {RMS }}$ & $\mathrm{I}_{\mathrm{A}}$ & $\mathrm{I}_{\mathrm{C}}$ & $\mathrm{SED}$ & $\mathrm{CAV}$ \\
$\mathbf{a}$ & 7309.9 & 1990.5 & 53622.0 & 1.2 & 492.4 & 165823.0 & 11.3 & $2.00 \mathrm{E}+07$ & 48208.0 \\
$\mathbf{b}$ & 0.581 & 0.879 & 1.165 & 0.684 & 1.015 & 1.414 & 1.049 & 2.075 & 0.799 \\
\hline
\end{tabular}

Table 5. $\mathrm{R}^{2}$ values obtained from the correlation of $\mathrm{I}_{\mathrm{D}-\mathrm{PGV}} \mathrm{IM}$ and MIDR.

\begin{tabular}{cc} 
Records & $\mathbf{R}^{\mathbf{2}}$ \\
\hline Original & 0.9341 \\
Scaled & 0.8793 \\
Matched & 0.0000002 \\
Original + Scaled & 0.9437 \\
All & 0.952 \\
\hline
\end{tabular}

Table 6. Linear correlation of the IMs used in this study for all the available records (original + scaled + matched).

\begin{tabular}{|c|c|c|c|c|c|c|c|c|c|c|}
\hline IMs & CAV & $\mathrm{I}_{\mathrm{A}}$ & $\mathrm{I}_{\mathrm{C}}$ & $I_{\text {D-PGV }}$ & PGA & PGV & $\mathrm{SA}_{\mathrm{T} 1}$ & SED & $\operatorname{acc}_{\mathrm{RMS}}$ & $\mathrm{vel}_{\mathrm{RMS}}$ \\
\hline CAV & 1.000 & & & & & & & & & \\
\hline $\mathrm{I}_{\mathrm{A}}$ & 0.978 & 1.000 & & & & & & & & \\
\hline $\mathrm{I}_{\mathrm{C}}$ & 0.890 & 0.934 & 1.000 & & & & & & & \\
\hline $\mathrm{I}_{\mathrm{D}-\mathrm{PGV}}$ & 0.778 & 0.820 & 0.801 & 1.000 & & & & & & \\
\hline PGA & 0.514 & 0.554 & 0.724 & 0.558 & 1.000 & & & & & \\
\hline PGV & 0.594 & 0.662 & 0.752 & 0.909 & 0.692 & 1.000 & & & & \\
\hline $\mathrm{SA}_{\mathrm{T} 1}$ & 0.572 & 0.609 & 0.635 & 0.717 & 0.487 & 0.723 & 1.000 & & & \\
\hline SED & 0.811 & 0.856 & 0.742 & 0.878 & 0.399 & 0.683 & 0.629 & 1.000 & & \\
\hline $\operatorname{acc}_{\mathrm{RMS}}$ & 0.553 & 0.626 & 0.854 & 0.582 & 0.780 & 0.683 & 0.509 & 0.444 & 1.000 & \\
\hline $\mathrm{vel}_{\mathrm{RMS}}$ & 0.619 & 0.678 & 0.831 & 0.802 & 0.652 & 0.844 & 0.671 & 0.667 & 0.856 & 1.000 \\
\hline
\end{tabular}


Table 7. IMs with correlations values $>0.80$.

\begin{tabular}{|c|c|c|c|c|}
\hline Correlation & Original records & Scaled records & Match records & All \\
\hline $\mathrm{CAV}-\mathrm{I}_{\mathrm{A}}$ & 0 & 0 & 0 & o \\
\hline $\mathrm{CAV}-\mathrm{I}_{\mathrm{C}}$ & o & o & - & o \\
\hline CAV - ID-PGV & o & - & - & - \\
\hline CAV - PGA & o & - & - & - \\
\hline CAV - PGV & o & - & - & - \\
\hline $\mathrm{CAV}-\mathrm{SAT} 1$ & o & - & - & - \\
\hline CAV - SED & o & o & o & o \\
\hline $\mathrm{CAV}-\operatorname{acc} \mathrm{RMS}$ & o & - & - & - \\
\hline CAV - velRMS & o & - & - & - \\
\hline $\mathrm{I}_{\mathrm{A}}-\mathrm{IC}_{\mathrm{C}}$ & o & o & o & o \\
\hline $\mathrm{I}_{\mathrm{A}}-\mathrm{I}_{\mathrm{D}-\mathrm{PGV}}$ & o & - & - & o \\
\hline $\mathrm{I}_{\mathrm{A}}-\mathrm{PGA}$ & o & - & - & - \\
\hline $\mathrm{I}_{\mathrm{A}}-\mathrm{PGV}$ & o & - & - & - \\
\hline $\mathrm{I}_{\mathrm{A}}-\mathrm{SA}_{\mathrm{T} 1}$ & - & - & - & - \\
\hline $\mathrm{I}_{\mathrm{A}}-\mathrm{SED}$ & o & o & o & o \\
\hline $\mathrm{I}_{\mathrm{A}}-\operatorname{acc} \mathrm{RMS}$ & o & - & - & - \\
\hline $\mathrm{I}_{\mathrm{A}}-\mathrm{vel}_{\mathrm{RMS}}$ & o & - & - & - \\
\hline $\mathrm{IC}_{\mathrm{C}}-\mathrm{ID}_{\mathrm{D}-\mathrm{PGV}}$ & o & - & - & o \\
\hline IC - PGA & o & - & - & - \\
\hline $\mathrm{I}_{\mathrm{C}}-\mathrm{PGV}$ & o & - & - & - \\
\hline $\mathrm{I}_{\mathrm{C}}-\mathrm{SA}_{\mathrm{T} 1}$ & - & - & - & - \\
\hline IC - SED & o & - & - & - \\
\hline $\mathrm{I}_{\mathrm{C}}-\operatorname{acc} \mathrm{RMS}_{\mathrm{R}}$ & o & - & - & o \\
\hline $\mathrm{I}_{\mathrm{C}}-\mathrm{vel}_{\mathrm{RMS}}$ & o & o & - & o \\
\hline ID-PGV - PGA & - & - & - & - \\
\hline ID-PGV - PGV & o & o & - & o \\
\hline $\mathrm{I}_{\mathrm{D}-\mathrm{PGV}}-\mathrm{SA}_{\mathrm{T} 1}$ & o & - & - & - \\
\hline ID-PGV - SED & o & o & - & o \\
\hline $\mathrm{I}_{\mathrm{D}-\mathrm{PGV}}-\mathrm{acc}_{\mathrm{RMS}}$ & - & - & - & - \\
\hline ID-PGV vel $_{\text {RMS }}$ & o & o & - & o \\
\hline PGA - PGV & o & - & - & - \\
\hline PGA - SAT1 & - & - & - & - \\
\hline PGA - SED & - & - & - & - \\
\hline PGA - accRMS & o & - & - & - \\
\hline PGA - vel RMS & o & - & - & - \\
\hline $\mathrm{PGV}-\mathrm{SA}_{\mathrm{T} 1}$ & o & - & - & - \\
\hline PGV - SED & o & - & - & - \\
\hline PGV - accRMS & o & - & - & - \\
\hline PGV - vel RMS & o & o & - & o \\
\hline SAT1 - SED & o & - & - & - \\
\hline $\mathrm{SA}_{\mathrm{T} 1}-\operatorname{accRMS}$ & - & - & - & - \\
\hline $\mathrm{SA}_{\mathrm{T} 1}-\mathrm{vel}_{\mathrm{RMS}}$ & o & - & - & - \\
\hline SED - accRMS & - & - & - & - \\
\hline SED - velRMS & o & o & - & - \\
\hline accRMS $-v_{\text {elR }}$ & o & - & o & o \\
\hline
\end{tabular}


Table 8. Beam and column sections of the first floor per number of stories. American wide flanges steel sections - ASTM A992.

\begin{tabular}{ccccccc}
\hline Number of stories & Beam sections & Area $\left(\mathbf{m}^{2}\right)$ & Inertia $\left(\mathbf{m}^{\mathbf{4}}\right)$ & Column sections & Area $\left(\mathbf{m}^{2}\right)$ & Inertia $_{\left(\mathbf{m}^{4}\right)}$ \\
\hline 3 & $\mathrm{~W} 14 \times 68$ & $1.30 \mathrm{E}-02$ & $3.03 \mathrm{E}-04$ & $\mathrm{~W} 18 \times 97$ & $1.84 \mathrm{E}-02$ & $7.26 \mathrm{E}-04$ \\
4 & $\mathrm{~W} 14 \times 74$ & $1.41 \mathrm{E}-02$ & $3.34 \mathrm{E}-04$ & $\mathrm{~W} 18 \times 106$ & $2.01 \mathrm{E}-02$ & $7.95 \mathrm{E}-04$ \\
5 & $\mathrm{~W} 18 \times 86$ & $1.64 \mathrm{E}-02$ & $6.42 \mathrm{E}-04$ & $\mathrm{~W} 18 \times 119$ & $2.26 \mathrm{E}-02$ & $9.12 \mathrm{E}-04$ \\
6 & $\mathrm{~W} 18 \times 86$ & $1.64 \mathrm{E}-02$ & $6.42 \mathrm{E}-04$ & $\mathrm{~W} 21 \times 132$ & $2.50 \mathrm{E}-02$ & $1.34 \mathrm{E}-03$ \\
7 & $\mathrm{~W} 16 \times 89$ & $1.71 \mathrm{E}-02$ & $5.50 \mathrm{E}-04$ & $\mathrm{~W} 21 \times 147$ & $2.79 \mathrm{E}-02$ & $1.51 \mathrm{E}-03$ \\
8 & $\mathrm{~W} 16 \times 89$ & $1.71 \mathrm{E}-02$ & $5.50 \mathrm{E}-04$ & $\mathrm{~W} 24 \times 146$ & $2.77 \mathrm{E}-02$ & $1.91 \mathrm{E}-03$ \\
9 & $\mathrm{~W} 18 \times 97$ & $1.84 \mathrm{E}-02$ & $7.26 \mathrm{E}-04$ & $\mathrm{~W} 24 \times 146$ & $2.77 \mathrm{E}-02$ & $1.91 \mathrm{E}-03$ \\
10 & $\mathrm{~W} 18 \times 97$ & $1.84 \mathrm{E}-02$ & $7.26 \mathrm{E}-04$ & $\mathrm{~W} 27 \times 161$ & $3.06 \mathrm{E}-02$ & $2.61 \mathrm{E}-03$ \\
11 & $\mathrm{~W} 18 \times 97$ & $1.84 \mathrm{E}-02$ & $7.26 \mathrm{E}-04$ & $\mathrm{~W} 27 \times 161$ & $3.06 \mathrm{E}-02$ & $2.61 \mathrm{E}-03$ \\
12 & $\mathrm{~W} 18 \times 106$ & $2.01 \mathrm{E}-02$ & $7.95 \mathrm{E}-04$ & $\mathrm{~W} 30 \times 173$ & $3.28 \mathrm{E}-02$ & $3.41 \mathrm{E}-03$ \\
13 & $\mathrm{~W} 18 \times 106$ & $2.01 \mathrm{E}-02$ & $7.95 \mathrm{E}-04$ & $\mathrm{~W} 30 \times 173$ & $3.28 \mathrm{E}-02$ & $3.41 \mathrm{E}-03$ \\
\hline
\end{tabular}

Table 9. Properties of the variables considered in the probabilistic NLDA.

\begin{tabular}{ccc}
\hline Variable & $\mu(\mathrm{kPa})$ & $\sigma(\mathrm{kPa})$ \\
\hline$L L$ & 2.0 & 0.2 \\
$S L$ & 3.50 & 0.175 \\
$f y$ & $4.2 \mathrm{E}+06$ & $2.1 \mathrm{E}+05$ \\
$E S$ & $2 \mathrm{E}+08$ & $2 \mathrm{E}+07$ \\
\hline
\end{tabular}

Table 10. Comparison of $\mathrm{R}^{2}$ values from the correlation of the studied IMs and MIDR obtained through the first approach and probabilistic NLDA.

\begin{tabular}{ccc}
\hline IMs & $\mathbf{R}^{2}-$ First approach & $\mathbf{R}^{\mathbf{2}}$ - Probabilistic NLDA \\
\hline PGA & 0.630 & 0.783 \\
PGV & 0.928 & 0.924 \\
SA $_{\mathrm{T} 1}$ & 0.856 & 0.873 \\
acc RMS $_{\text {vel }}$ RMS & 0.739 & 0.768 \\
IA $_{\text {I }}$ & 0.940 & 0.919 \\
IC & 0.834 & 0.862 \\
SED & 0.818 & 0.802 \\
CAV & 0.950 & 0.928 \\
ID-PGV & 0.828 & 0.853 \\
\hline
\end{tabular}

